\title{
Self-Prediction: Exploring the Parameters of Accuracy
}

\author{
Timothy M. Osberg \\ Niagara University
}

\author{
J. Sidney Shrauger \\ State University of New York at Buffalo
}

\begin{abstract}
We conducted four studies to explore people's self-prediction processes. Study I examined the types of information people report using when making self-predictions. Five categories of information were determined. Studies 2 and 3 examined the relation between the use of different categories of information and self-prediction accuracy. Using correlational and experimental methodologies, these two studies demonstrated the utility of attending to personal base rate and personal disposition information in formulating accurate self-predictions. Individual differences in accuracy as a function of public and private self-consciousness were also evident. Study 4 found that more certain selfpredictions, as well as predictions that were distinct from what was expected for the average individual, were more accurate. Overall, the findings suggest the importance of attending to individuating information in formulating accurate self-predictions.
\end{abstract}

The traditional model of psychological assessment emphasizes the use of trained evaluators to formulate predictions about a person on the basis of testing data, historical information, and clinical judgment. To date, however, there has been much controversy and debate over the utility of efforts in the fields of personality and clinical psychology aimed at developing instruments to aid in behavior prediction (cf. Rorer \& Widiger, 1983). Questions have been raised about the cross-situational predictive accuracy of traditional assessment techniques (Mischel, 1968), the adequacy of most professionals' abilities to integrate information with optimal weightings (e.g., Wiggins, 1973), and the potential biases prevalent in the inferences drawn from test data (Chapman \& Chapman, 1967). Nevertheless, the standard method for assessment remains the intuitive appraisal of an external evaluator. Some writers have cautioned us about the conclusions we draw from research investigations into the nature of personality that use some of our most triedand-true personality assessment devices (Nicholls, Licht, \& Pearl, 1982), whereas others have warned us about the potential for thoughtlessness in measurement-based personality research (Hogan, Hogan, Briggs, \& Jones, 1983).

\section{Convergence Toward a Viewpoint Supporting Greater Use of Self-Assessment}

Fueled by some of these continuing sources of dissatisfaction with assessment, several theorists, in taking stock of the field's

This article is based in part on the first author's doctoral dissertation, which was submitted in partial fulfillment of the requirements for the Ph.D. degree at the State University of New York at Buftalo. The authors would like to thank Nancy Johnson, Brenda Major, and Michael Raulin for their helpful comments during the design of this research. The help of Kathleen Nielsen, Joel Snitzer, and Janet Mather in running the project is gratefully acknowledged. Appreciation is also extended to Susan Mason and two anonymous reviewers for their helpful comments on an earlier version of this article.

Correspondence concerning this article should be addressed to Timothy M. Osberg, Department of Psychology, Niagara University, Niagara University, New York 14109. current status, have shown a striking convergence in their recommendations for the future (Burisch, 1984; Dana, 1984; Korchin \& Schuldberg, 1981; Lanyon, 1984; Mischel, 1977; Rorer \& Widiger, 1983). All suggest, albeit in varying degrees, that greater attention to people's own self-assessments or predictions could provide greater validity than do more traditional means of predicting behavior. For example, Mischel (1977), in the context of calling for the use of the individual as "expert and colleague" in the process of assessment, wrote that "our "subjects' are much smarter than many of us thought they were. Hence, if we don't stop them by asking the wrong questions, and if we provide appropriate structure, they often can tell us much about themselves and, indeed, about psychology itself" (p. 249).

Korchin and Schuldberg (1981) suggested "more respectful attention to the person's own views of his or her character, problems, and situation than simple reliance on external measures (whether they be objective tests, projective techniques, or behavioral observations)" (p. 1156). Rorer and Widiger (1983) stated the view succinctly: "In general, if you want information from someone, the best way to get it is to ask them" (p. 433). Burisch (1984) has told us that "if you ask subjects to rate themselves directly on simple trait-rating scales, these self-ratings turn out, on average, to be more valid than corresponding questionnaire scales" (p. 225).

Dana (1984) identified this movement toward self-assessment as a "megatrend" in personality research and Lanyon (1984) called it "overdue." What all of these views seem to suggest is a return to Gordon Allport's (1942) often cited dictum: "If we want to know how people feel: what they experience and what they remember, what their emotions and motives are like, and the reasons for acting as they do-why not ask them" (p. 37).

The validity of self-assessments has been widely debated for some time, and varying conclusions have been drawn. The dominant view has often been that people are either unwilling or unable to provide valid information about themselves. Skepticism has come from those concerned about the self-presentational aspects of self-description (e.g., Schlenker, 1980), particularly the tendency for people to present themselves in socially 
desirable ways (Crowne \& Marlowe, 1964; Edwards, 1957). The psychoanalytic viewpoint has assumed that people do not have adequate insight into many of the most important processes that influence their behavior, particularly unconscious ones. Still others contend from a broader perspective that there are a number of biases and shortcomings in human inference processes (e.g., Kahneman \& Tversky, 1973; Nisbett \& Ross, 1980; Nisbett \& Wilson, 1977; Ross, 1977; Bradley, 1978).

Another view is taken, however, by those who argue that selfrelevant information is particularly abundant and salient to the individual and that we are highly motivated to obtain information about our skills and personal competence (e.g., Trope, 1983). The abundance of information we have available about ourselves relative to other people seems self-evident. Certainly, with a lifetime of self-observation people have a vast amount of evidence, with respect to both their actions and internal states, on which to base judgments about their behavior.

Not only is self-relevant information extensive, but it also seems particularly salient and important to people. A number of studies have suggested that information about the self is remembered more quickly and accurately than information about others, thereby suggesting that people may have better access to relevant data when judging themselves than when judging others (e.g., Bower \& Gilligan, 1979; Kuiper, 1981; Markus, 1977; Markus, Crane, Bernstein, \& Siladi, 1982; Rogers, Kuiper, \& Kirker, 1977).

It also appears that people may tend to seek out information that has particular relevance for predicting their future behavior. Some theorists suggest that people may naturally engage in self-assessment processes as a means of maximizing interpersonal functioning (e.g., Trope, 1983; Wicklund \& Gollwitzer, 1983). Trope (1983), for example, discussed the importance of reducing uncertainty about one's own abilities as a factor in determining the type of information people seek about themselves. The desire to assess one's personal attributes, in order to predict performance in a variety of situations, may be one of the most central manifestations of the general motive proposed by cognitive theorists, such as Kelly (1955), to anticipate events as a means of developing a better understanding of and greater sense of control over the world around us.

These arguments and evidence supporting the potential predictive value of self-appraisals are buttressed by research comparing the relative accuracy of self-assessments with more traditional approaches to assessment in the prediction of behavior. In reviewing this work, Shrauger and Osberg (1981) concluded that in many important areas, such as the prediction of vocational choice, academic achievement, job performance, peer ratings, reactions to psychotherapy, and adjustment following psychiatric hospitalization, self-assessments are at least as predictive as traditional assessment methods, if not more. Researchers in a number of areas have begun to recognize that selfassessments often show a striking correspondence with more objective data, such as the correspondence found in the study of such diverse phenomena as alcoholism (Sobell \& Sobell, 1975, 1978), depression (Billings, Cronkite, \& Moos, 1983; Lewinsohn, Mischel, Chaplin, \& Barton, 1980), insomnia (Coates et al., 1982), return rates to prison (U.S. Department of Justice, 1985), and weight control (Stunkard \& Albaum, 1981).

\section{Toward a Better Understanding of Self-Prediction Processes}

Despite the numerous calls for greater reliance on self-assessment and the evidence attesting to its relative validity, surprisingly little is known about how people formulate self-assessments and about the factors that influence their accuracy. In the present research, we report explorations of this alternate approach to psychological assessment that are aimed at greater use of individuals' self-judgments in the prediction of behavior.

The variables that might influence the accuracy of self-predictions can be categorized into three general areas: (a) properties of specific behaviors being predicted; (b) individual differences in reactions to particular behaviors; and (c) attributes of people making predictions. Looking at the first area, because there are a host of behaviors or events in one's life that might be predicted usefully, it is important to know whether certain events can be judged more accurately than others and to determine the properties that relate to the predictability of these events. One general determinant of the predictability of certain events or behaviors would seem to be the extent to which relevant information is available to serve as the basis for the individual's prediction. The literature on the relation between expressed attitudes and behavior, for example, consistently indicates that the correspondence between attitudes and behavior is greater when the individual has had more direct exposure to the situations about which attitudes are being assessed (see Fazio \& Zanna, 1981 for a review).

In considering the availability of information, it also seems important to explore the types of information to which people typically attend when they are making judgments and to examine the value of different information for making accurate predictions. Various behaviors or events being predicted may differ not only in the amount of information available but also in their likelihood of occurrence. Previous investigations (Shrauger \& Osberg, 1982) have indicated that accuracy of predictions is correlated substantially with the frequency of the event's occurrence. Events that have very high or very low base rates of occurrence are more predictable than those with base rates that lie more in the middle range. Other factors, such as the importance of the target behaviors, have also been found to be related to their predictability, whereas dimensions such as the events' social desirability or degree of internal control have not.

Although some events may tend to be judged more accurately than others, there may also be important interrelationships between the event and the individual judging it that have a substantial impact on accuracy. For example, some people may be able to predict their social relationships very well but have little ability to make forecasts about their health, whereas others' accuracy may follow the opposite pattern. The amount of information available about different areas, the importance ascribed to those areas, confidence in one's judgments, and a variety of other factors might produce these interactions between the types of events and the nature of the individual making predictions.

It is also possible that certain types of individuals are generally more accurate judges than others. Although individual differences in accuracy are only moderately stable across events (Shrauger \& Osberg, 1982), certain personality attributes might 
well be associated with the validity of self-appraisals. People's levels of introspectiveness, their degree of defensiveness or selfdeceptiveness, and their impulsivity or consistency in action may all be relevant. Knowledge of such factors would be helpful in deciding which predictions are most likely to be accurate.

In the series of investigations to be reported in this article, several major issues in the study of self-prediction were explored. First, attention was given to the process of self-prediction, with the goal of identifying some of the strategies best suited to the formulation of accurate self-appraisals of potential future behavior. Second, an attempt was made to identify some of the individual difference variables that relate to accuracy (for it is not assumed that all individuals will be accurate self-predictors). Finally, some of the properties of self-predictions that may serve as cues to the accuracy of such judgments were examined because it is important for professionals to know when to rely on a person's self-predictions.

Study 1 explored the specific types of information people use as a basis for making self-predictions. The categories of information obtained in Study 1 were then used in Study 2, where subjects were asked to indicate the information they used in making a number of self-predictions whose accuracy was subsequently assessed. Scores on an individual difference measure of public and private self-consciousness were also examined for their potential relations to overall accuracy. Study 3 then attempted to determine whether the accuracy of subjects' selfpredictions could be enhanced by directing them to attend to specific types of information from among the categories obtained in Study 1. Finally, Study 4 examined the properties of self-predictions associated with accuracy such as certainty of prediction and the distinctiveness of the prediction.

\section{Study 1}

The primary goal of this investigation was to examine people's perceptions of the types of information they use when making self-predictions. Subjects were asked to make a series of self-predictions and then to indicate the information they used to arrive at their predictions. The purpose was to obtain descriptive data that could be used in subsequent investigations to determine which information usage strategies lead to the most accurate self-predictions.

Little is known about the nature of the data people draw on when formulating self-predictions. Some theorists have speculated that attention to past behavior is one often used source of information and, perhaps, is most likely to result in maximally valid self-predictions (Pryor, 1980). Such claims, however, have not been backed by data. In addition, attention to population norms (or the base rate for a behavior) remains a likely source of information to which people may attend in judging their own potential future behavior. Kahneman and Tversky (1973), however, have demonstrated people's disinclination to use base-rate information in predictions regarding the behavior of others. They noted that individuals typically ignore base rates in favor of more individuating but presumably less diagnostic information. Study 1 allowed us to determine whether this tendency extends to the types of information people spontaneously attend to when making predictions of their own behavior.

Personality differences in the types of information used were also examined. Previous research (Shrauger \& Osberg, 1982) has shown individual differences in self-confidence and selfconsciousness relate to the accuracy of self-prediction, with high self-confidence, high-private self-consciousness and lowpublic self-consciousness found to be related to greater accuracy. Therefore, potential individual differences in information strategies used as a function of these dimensions were explored.

\section{Method}

Subjects. Twenty-three male and 25 female undergraduates participated in this study to partially fulfill an introductory psychology course requirement. All subjects were run individually. Earlier in the semester, all but 5 subjects had completed the Self-Consciousness Scale (Fenigstein, Scheier, \& Buss, 1975). This scale measures three aspects of dispositional self-attention processes: private self-consciousness, public self-consciousness, and social anxiety. The present research focused on the first two aspects of self-awareness as they related to self-prediction processes. Private self-consciousness refers to the tendency to direct attention to one's own thoughts, feelings, and motives (e.g., "I'm always trying to figure myself out"). Public self-consciousness reflects the awareness of oneself as a social object (e.g., "I'm concerned about the way I present myself"). All but 3 subjects had completed the Personal Evaluation Inventory, a measure of self-confidence recently developed by Shrauger (1985).

Procedure. Upon arrival for the study, subjects were told that they would be asked to complete a questionnaire that involved predicting the likelihood of various life events or behaviors during the next 2 months and that following this they would be interviewed about their ratings. The subjects then made self-predictions by responding, on a 4 point scale of increasing likelihood (ranging from definitely will not occur to definitely will occur), to an 80-item inventory of events or behaviors that was used previously by Shrauger and Osberg (1982). The items were directed toward a college population and sampled a variety of areas including: interpersonal relationships, psychological functioning, religious behavior, academic performance, recreation, health-related behavior, intimate relationships, diet, changes in lifestyle, economic functioning, and drug/alcohol use. Following their predictions, subjects were interviewed about the information they used in making their predictions. For this phase, a sample of 20 items from the longer measure was used (see Table 1) because it was judged that inquiring about all 80 items would be too time consuming. These 20 items were chosen as representing the range of content areas contained in the longer inventory. The interviewer presented each item followed by the standard question: "What kind of information did you draw on or attend to in predicting whether or not (Event X) would occur?" The standard probe "Could you tell me more about that?" was used occasionally when subjects' responses were unclear or did not follow directions. All responses were recorded via audiotape and later were transcribed verbatim.

\section{Results}

The first author and two trained assistants served as independent raters in the coding of subjects' responses. A two-stage process of content analysis was then applied to the data (Weber, 1985). During the initial stage, each of the three raters independently read all of the responses and attempted to formulate a set of categories into which responses could be placed. The second stage involved pooling the raters' categories and attempting to determine a final set of categories. To do this, similar categories were combined, and only categories suggested by at least two of the raters were retained. This process yielded a five-category system applicable to the data. 
Table 1

The Subset of 20 Items About Which the Informational Bases of Subjects' Self-Predictions Were Elicited

1. Become very upset with or had an argument with a close friend.

2. Gone to services at a church or synagogue.

3. Been a patient in a hospital or infirmary because of some physical problem.

4. Introduced yourself to someone you were attracted to.

5. Started to play a new sport or physical activity you had not done before.

6. Offered advice to a friend concerning his or her romantic relationship.

7. Skipped a class because you simply did not feel like attending.

8. Will not have had enough money to pay an important bill.

9. Said something in class which the instructor or another class member criticized or disagreed with.

10. Made a joke or humorous comment in a group of at least 5 or more people which they laughed at.

11. Will have written a paper, done a project, or done an exam that you felt was the best you had ever done.

12. Changed your hairstyle or type of haircut.

13. Will have been unable to sleep for at least an hour after going to bed because you were thinking about some important decision or event.

14. Gotten high on some type of drug besides alcohol.

15. Will have ended a romantic relationship.

16. Have fallen in love.

17. Have had period of a day or more when you could get very little done because you felt too down and discouraged.

18. Eaten a type of food you have never had before.

19. Gone to a movie.

20. Been rejected by a group of people who are important to you.

The first author assigned each of the 960 responses to one of the categories. To assess reliability of these ratings, the other two judges rated a random sample of 240 of the items. The sample was drawn to include $25 \%$ of each subject's responses. The agreements between the first author and the other judges were $87 \%$ and $80 \%$. Since the average agreement was $83.5 \%$, the analyses included only the first author's data. ${ }^{1}$

Table 2 displays the category titles, descriptions, and examples of responses coded into each category and the overall percentages of items placed into each category on the basis of the complete data for all 48 subjects, as categorized by the first author.

Some individual differences in the use of the information categories were obtained. A sex difference in basing self-predictions on personal disposition information emerged. The mean percentage of use for male subjects was $13.9 \%$ as opposed to $20.1 \%$ for female subjects, $t(46)=2.44, p<.01$. A difference in the use of personal base-rate information between high and low self-confidence subjects (on the basis of a median split) also was apparent. High-confidence subjects used this information $45.6 \%$ of the time compared with $35.7 \%$ for low-confidence subjects, $t(43)=2.25, p<.03$. Finally, high $(14.7 \%)$ and low $(20.2 \%)$ private self-consciousness subjects (on the basis of a median split) differed significantly in the use of personal disposition information, $t(41)=1.80, p<.05$.

\section{Discussion}

Study 1 demonstrated that free-response data about information used in self-predictions can be reliably categorized within a five-category system that accounts for $94 \%$ of the responses generated. Consistent with previous speculation (Pryor, 1980 ), a large portion ( $41 \%$ ) of responses indicated that predictions were based on an assessment of the frequency of individuals' past relevant behavior. Subjects tended to use their own previous actions as an anchor against which they indicated the likelihood of the recurrence of comparable behavior. It was also evident that they tended to make inferences on the basis of specific previous behavior or particular circumstances they anticipated might occur rather than on the basis of their ascription of global attributes to themselves. Men, in particular, showed this pattern, which suggests a reluctance to conceptualize their behavior in terms of global dispositions as opposed to more circumscribed situational explanations. Such a pattern resembles that found in the actor-observer literature (Jones \& Nisbett, 1971 ; see Watson, 1982 for a review), although the present study does not allow such direct comparisons because predictions of others' behavior were not examined.

Also, consistent with the prior literature in decision theory (Kahneman \& Tversky, 1973) and social cognition (Nisbett \& Borgida, 1975) was the finding that population base rate or consensus information was relatively ignored as a basis for self-prediction. This finding should be tempered, however, by the observation that, in using personal base-rate data, subjects may have implicitly used perceived information about population base rates. Although such implicit usage could not be detected, in those instances where subjects explicitly drew on both types of information (e.g., "I'm not likely to be arrested in the next 2 months because that is a relatively infrequent event for anyone including me"), they were scored as having used both.

Predictions based on the specific intention to perform a behavior were relatively infrequent. This finding seems interesting in light of recent research suggesting that individuals' intentions are poorer predictors of their behavior than are measures that more directly assess the perceived likelihood of various behaviors (Warshaw \& Davis, 1985).

The results of this study, combined with those of an earlier investigation by Major (1980), suggest that the informational bases of self-predictions have much in common with those involved in the retrospective causal analysis of other people's behavior. Major's investigation examining the causes of others' behavior explored the relative use of distinctiveness, consensus, and consistency information associated with Kelley's (1967; 1973) theory of attribution. These three categories of information are similar to the personal disposition, population baserate, and personal base-rate categories, respectively, in the present study. Strikingly similar patterns of information usage are reported both in the present study and in Major's study. In both studies, consensus or population base-rate information was used least often, and consistency or personal base rate was the most widely used category. For this latter comparison, the percentages of use were very similar- $41 \%$ in the present study and $38 \%$ in Major's.

\footnotetext{
${ }^{1}$ Within the sample of items used to assess reliability, the percentages of responses placed into each category by the other two raters closely matched the first author's data. Percentages for the first rater were $40 \%$, $38 \%, 16 \%, 2 \%, 1 \%$, and percentages for the second rater were $46 \%, 29 \%$, $17 \%, 5 \%, 1 \%$.
} 
Table 2

Information Category Titles, Descriptions, and Examples, Along With Percentages of Responses Coded Into Each Category

Category

Description

Examples
$\%$ of responses coded into category
The past frequency with which the event or behavior has occurred.

Circumstances

Assessment of the likelihood that certain conditions that enhance or reduce the likelihood of the behavior will occur.

\begin{abstract}
Personal dispositions
Knowledge of one's own personal qualities or dispositions.
\end{abstract}

Intention

Population base rate
The specific intention of whether or not to perform a behavior.

The frequency of the behavior or event in the general population.

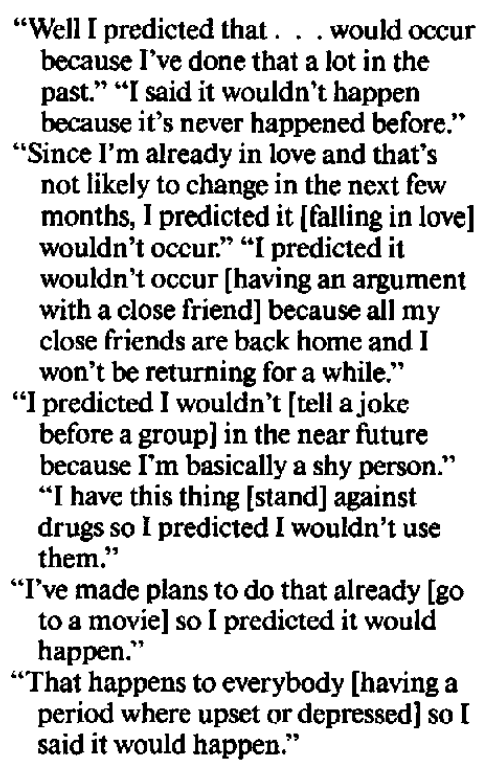

"Well I predicted that . . . would occur because I've done that a lot in the past." "I said it wouldn't happen because it's never happened before."

"Since I'm already in love and that's not likely to change in the next few months, I predicted it [falling in love] wouldn't occur." "I predicted it wouldn't occur [having an argument with a close friend] because all my close friends are back home and I won't be returning for a while."

"I predicted I wouldn't [tell a joke before a group] in the near future because I'm basically a shy person." "I have this thing [stand] against drugs so I predicted I wouldn't use them."

"I've made plans to do that already [go to a movie] so I predicted it would happen."

"That happens to everybody [having a period where upset or depressed] so I said it would happen."

41

\section{Study 2}

The goal of Study 2 was to determine which types of information usage are associated with the formulation of accurate self-predictions. Thus, the relative degrees of accuracy associated with attending to personal base rates, circumstances information, personal dispositions, and population base rates were compared. These categories were chosen because they included the three most frequently used categories of information and, in the case of population base-rate information, because it was of theoretical interest given previous research on the use of these data. In addition, potential individual differences in self-prediction accuracy were examined. These issues were explored using a design wherein subjects were asked to make a series of predictions concerning various behaviors, to report the types of information to which they attended when making these predictions, and to return 2 months later to report the occurrence or nonoccurrence of each behavior.

Previous findings documenting the relation of accuracy to the population base rate of a behavior (Shrauger \& Osberg, 1982) suggest that attention to this type of information is likely to enhance accuracy. Although the population base rate of a behavior may be a good indicator of one's likelihood of engaging in that behavior, an even better indicator may be, as others have speculated (Pryor, 1980), the frequency with which one has engaged in that behavior in the past. Some support exists for this prediction. Regan and Fazio (1977) have demonstrated that the self-reported attitudes of people instructed to recall their past behavior on some dimension showed a better fit with later actual behavior than was true for people given no such instructions.

The usefulness of personal or population base-rate infor- mation for the formulation of accurate self-predictions, however, might well be a function of the nature of the behaviors being predicted. One would expect attention to base-rate information to be most useful for behaviors that have extreme base rates. For behaviors with base rates more in the middle range, attention to one's individual attributes rather than to attributes of the behaviors may be more useful. To test these assumptions, the usefulness of using personal or. population base-rate information for predicting behaviors with extreme base rates versus ones having base rates in the middle range was examined.

As well as attention to personal base rates, attention to one's own personal dispositions may also represent an effective approach to formulating accurate self-predictions. Such information may represent a highly evolved type of data based on extensive self-observation of previously noted consistencies in one's own behavior.

In addition to the predictions concerning information usage and accuracy, we also predicted that high private self-consciousness and low public self-consciousness would relate to enhanced self-prediction accuracy because past research had found these dimensions to be associated with greater self-report validity (Scheier, Buss, \& Buss, 1978; Shrauger \& Osberg, 1982; Turner, 1978). ${ }^{2}$

\section{Method}

Subjects. Twenty-seven male and 35 female undergraduates participated in this study to partially fulfill an introductory psychology course

\footnotetext{
${ }^{2}$ In addition, internal-external control (Rotter, 1966) and self-confdence were examined for their potential relations to self-prediction accuracy, but because no effects were found, these dimensions will not be discussed further.
} 
requirement. Approximately two thirds of the sample had completed the Self-Consciousness Scale (Fenigstein et al., 1975) at an earlier, mass testing session.

Procedure. Subjects signed up in class for a two-part "life events study." At the first session, subjects' predictions concerning the likelihood of occurrence of a series of events or behaviors were obtained. They returned 8 to 9 weeks later to report whether or not each event had in fact occurred. Because of the self-report nature of the criterion measure, the self-prediction focus of the study was disguised so that subjects' desires to appear consistent or accurate from one set of ratings to the next would be minimized. They were informed that their role would be to aid in the development of a new questionnaire designed to assess the impact of various life events on people. Subjects were told that they would be asked to rate each event listed on the life events questionnaire at the first session, and upon returning near the end of the semester, they would be asked to make further ratings. The testretest design was justified by telling subjects that their first set of ratings would be used to refine the questionnaire and would determine which further ratings would be necessary. Subjects' predictions involved their rating the likelihood that each event on the life events questionnaire would occur during the ensuing 2 months. These ratings were made on the same 4-point scale of increasing likelihood described in Study 1. The inventory was an adaptation of the one used in Study 1. It listed 55 different events or behaviors (see Appendix). The rationale given for obtaining these predictions centered on the investigators' interest in examining people's reactions to the events, including their rated likelihood of occurrence.

Instead of considering the prediction of more circumscribed behaviors that might occur in the laboratory, judgments of naturally occurring events were explored even though the occurrence of these events may have been influenced by a variety of uncontrolled and unspecifiable factors. We chose this strategy because the kinds of judgments required seemed closer to those typically demanded in assessment situations and because the most relevant motivational and cognitive parameters influencing such molar judgments might well differ from those that are most prominent in laboratory assessments of discrete events. Sampling a wide range of events in the individual's ongoing life situation required the use of subjects' self-reports as the criterion measure. The potential problems with such a criterion seemed to be outweighed by the fact that alternative approaches would have entailed restricting the scope and range of the events being evaluated, thereby placing sharp limits on generalization. In addition to disguising the focus on self-prediction accuracy, several other precautions were taken to minimize invalid reporting of the occurrence or nonoccurrence of events. These included establishing strong demands for candor, ensuring confidentiality, and selecting events whose occurrence was quite easily discernible.

After making their predictions, subjects were asked to indicate the type or types of information on which they based each prediction. For these ratings, they chose, from a list containing the four types of information discussed earlier, the one or two most important types of information they used to determine each prediction. The following list of alternatives was used for these ratings:

A. I thought about how frequently it has happened to me in the past.

B. I thought about whether or not I'm the kind of person who would do that.

C. I thought about how likely it was to happen to anyone.

D. I thought about, based on the future circumstances of my life, whether it was likely to happen.

Leave Blank-None of the above.

The order of the choices was counterbalanced across subjects. Quantitative scores were then assigned to indicate the degree to which each type of information was used for each prediction. A score of 6 points was assigned to the top choice and 3 points were awarded to the second choice. Nine points were awarded if the specified information category was the only one reported as being used.

At the final session, subjects reported the occurrence or nonoccurrence of each of the 55 events or behaviors. They were told to report that the event had occurred only if they could remember a specific instance of the event happening during the previous 2-month interval. The rationale presented for collecting the occurrence/nonoccurrence ratings was the investigators' interest in understanding the actual frequency of each event in an average student population.

Following the completion of the occurrence/nonoccurrence ratings, subjects responded to a brief open-ended questionnaire that assessed their reactions to participating in the study. One item assessed subjects' perceptions of the purpose of the study. This permitted a determination of how well the subjects were diverted from a focus on the measurement of accuracy in self-prediction. Three subjects did report suspecting at some level that the study examined the issue of accuracy. The mean number of accurate predictions for these subjects did not differ from that for the total sample. Because the major analyses, both including and deleting these subjects, did not differ, the results reported are based on the total subject sample.

\section{Results and Discussion}

To assess accuracy, we scored an item as a hit if it was predicted definitely or probably to occur and did, or if it was predicted definitely or probably not to occur and did not. Self-prediction accuracy was thus measured by comparing individuals' predictions with their reported behavior. The total number of hits was the main measure of accuracy.

Turning first to the results bearing on the relation between attending to different types of information and subsequent accuracy, the mean use scores for each category of information (across all subjects for each behavior) were correlated with the percentage of subjects who correctly predicted each behavior. In this way it was possible to evaluate whether greater use of certain types of information was associated with enhanced accuracy. Because previous research (Shrauger \& Osberg, 1982) documented a relation between the extremity of the base-rate occurrence of behaviors and the extent to which they could be predicted accurately, we made an effort to control for the effects of actual base rates in exploring the relation between information use and accuracy. Thus, correlational analyses were carried out across all behaviors as well as separately for behaviors with extreme base rates and ones with base rates in the middle range.

The extremity of a behavior's base rate was determined by using the absolute value of the difference between the behavior's actual rate of occurrence in the sample and a $50 \%$ rate of occurrence. For example, behaviors in this sample with rates of occurrence of $65 \%$ and $35 \%$ would both be scored as 15 . Thus, behaviors with more extreme base rates yielded higher scores. A median split was then performed to separate extreme baserate behaviors $(n=27)$ from midrange base-rate behaviors $(n=28)$.

Table 3 summarizes the major results on this issue. As can be seen, quite modest associations exist between information use and accuracy across all behaviors. Modest positive correlations of use and accuracy were found for personal base rate and personal dispositions information, whereas modest to strong negative associations were found for population base-rate infor- 
Table 3

Correlations Between Accuracy and Use of Each Information

Category Across All Items, Within Middle-Range

Base-Rate Behaviors Only, and Within

Extreme Base-Rate Behaviors Only

\begin{tabular}{|c|c|c|c|c|}
\hline \multirow[b]{2}{*}{$\begin{array}{l}\text { Information } \\
\text { category }\end{array}$} & \multicolumn{3}{|c|}{ Behaviors } & \multirow[b]{2}{*}{$\begin{array}{l}Z \text { of difference } \\
\text { between mid- } \\
\& \text { extreme } \\
\text { range }\end{array}$} \\
\hline & $\begin{array}{c}\text { All } \\
(N=55)\end{array}$ & $\begin{array}{l}\text { Midrange } \\
\text { base-rate } \\
\text { only } \\
(n=27)\end{array}$ & $\begin{array}{c}\text { Extreme } \\
\text { base-rate } \\
\text { only } \\
(n=28)\end{array}$ & \\
\hline \multicolumn{5}{|l|}{ Personal } \\
\hline base rate & .19 & -.31 & $.55^{* * * *}$ & $3.24^{* * *}$ \\
\hline Personal & & & & \\
\hline dispositions & .13 & .31 & .01 & 1.07 \\
\hline \multicolumn{5}{|l|}{ Population } \\
\hline base rate & -.09 & -.09 & -.20 & $<1$ \\
\hline Circumstances & $-.31 *$ & -.03 & $-.47^{* *}$ & 1.66 \\
\hline
\end{tabular}

$* p<.03 .{ }^{* *} p<.02 .^{* * *} p<.01$.

mation and circumstances information. However, when these correlations were examined separately for midrange and extreme base-rate behaviors, there was a striking pattern of differential usefulness of some types of information for the two subsets of behaviors. The most significant comparison involved personal base-rate information that, as expected, had a highpositive association with accuracy among behaviors with extreme base rates but was negatively related to accuracy among midrange base-rate behaviors. The difference between these correlations was significant.

Personal disposition information, the only other type of information whose use was positively associated with accuracy, also showed a distinctive pattern for the two types of behavior. Its use was positively associated with accuracy for behaviors with base rates in the middle range and was unrelated to accuracy among extreme base-rate behaviors.

To better understand the distinctively different patterns of relations with accuracy for personal base-rate and personal disposition information, it is important to consider that attention to personal base rates may involve a specific assessment of the frequency of one's past relevant behavior and no necessary comparison of oneself with others, whereas attention to personal dispositions may represent more of an implicit contrasting of oneself with other people. Such an assumed difference in the bases of these two types of information remains somewhat speculative and deserves future empirical attention. The present findings do suggest, however, that for stereotyped behaviors wherein people tend to behave all in the same way (extreme base-rate behaviors), encouraging a person to attend to their own past frequency of behavior is most useful, but for behaviors showing much individual variation (midrange base-rate behaviors), encouraging attention to one's own dispositions or the ways that one is different from others is most useful.

The use of population base-rate information proved to be a consistently ineffective basis for self-predictions of both extreme and moderately frequent behaviors. Such data may not be particularly helpful when more individuating information is available. Thus, the apparent lack of attention to population base rates reported in Study 1 may be justified. Their lack of relevance in self-judgments, at least of the type reported here, may differ from their utility in judging other people where individuating data may often be minimal or irrelevant. Differences in the data bases for accurate predictions of self versus others should certainly continue to be explored.

The lack of utility in attending to circumstantial or situational information is interesting when one considers the wealth of research in the area of self-appraisal that suggests people tend to see themselves as responding to situational cues and not as acting on the basis of broad dispositions (e.g., Jones \& Nisbett, 1971; also, see Watson, 1982 for a review). Although self-assessment may be useful because it does not fall prey to the tendency to overgeneralize and ascribe broad dispositions independent of situational contexts, the current data suggest that specific attention to circumstantial or situational data is not associated with greater accuracy. More personalized assessments clearly were more associated with accuracy in self-prediction.

Concerning the relation between public and private self-consciousness and self-prediction accuracy, subjects were divided into high, medium, and low groups on each of these dimensions, and the mean total numbers of accurate self-predictions in each group were compared. The mean number of hits for each group is displayed in Table 4.

A significant main effect of public self-consciousness on accuracy was obtained, $F(2,39)=5.52, p=.01$. Newman-Keuls tests revealed that both the medium group-high group comparison as well as the low group-high group comparison were significant at the .05 level. It thus appears that, consistent with previous research (Turner \& Peterson, 1977) on self-report accuracy, high levels of public self-consciousness are associated with less accuracy in self-prediction. This finding also fits with the results of Wymer and Penner (1985) who found that subjects lower in other-directedness showed greater congruence between self-rated dispositions and actual behavior. Presumably, high public self-consciousness subjects are more attentive to selfpresentational concerns, and this then reduces the candor of their self-predictions.

The relation between private self-consciousness and accuracy was also explored, and although there was no main effect for this variable $(F<1)$, a significant Sex $\times$ Private Self-Consciousness interaction was obtained, $F(2,36)=3.33, p<.05$. The means associated with this interaction are displayed in Table 5. Separate simple effects tests carried out on male and female subjects revealed no significant effect for private self-consciousness among women $(F<1)$, but a trend toward a significant effect was observed for men, $F(2,19)=2.95, p<.08$. A comparison

Table 4

Mean Number of Self-Prediction Hits for the High, Medium, and Low Public Self-Consciousness Groups

\begin{tabular}{llc}
\hline $\begin{array}{c}\text { Public self- } \\
\text { consciousness } \\
\text { condition }\end{array}$ & $N$ & $\begin{array}{c}\text { Mean number of } \\
\text { self-prediction hits }\end{array}$ \\
\hline Low & 14 & 38.8 \\
Medium & 15 & 39.7 \\
High & 13 & 35.7 \\
\hline
\end{tabular}


Table 5

Mean Number of Self-Prediction Hits as a Function of Sex and Private Self-Consciousness

\begin{tabular}{cccc} 
& \multicolumn{3}{c}{ Private self-consciousness } \\
\cline { 2 - 4 } Sex & Low & Medium & High \\
\hline Male & & & \\
$M$ & 35.3 & 38.1 & 40.6 \\
$N$ & 7 & 10 & 5 \\
Female & 39.3 & 39.4 & 37.5 \\
$M$ & 7 & 5 & 8 \\
$N$ & & & \\
\hline
\end{tabular}

of the means among male subjects revealed that high-private men were more accurate than low-private men, $t(11)=2.58$, $p<.03$. An explanation for this differential pattern for men and women was not readily apparent.

Partial agreement was therefore found with the trend in previous research indicating that people higher in private self-consciousness tend to give more valid self-reports (Scheier et al., 1978; Shrauger \& Osberg, 1982; Turner, 1978). Because previous data had been based on the prediction of more circumscribed behaviors in the laboratory, the present research extended the findings on the relation of self-consciousness and self-report accuracy to include the prediction of a range of naturally occurring events.

The data from Study 2 are also consistent with those of Pryor, Gibbons, Wicklund, Fazio, and Hood (1977, Experiment 1) who found that a situational manipulation of self-attention processes enhanced the predictive accuracy of self-reports. These authors assumed that increased self-awareness enhances predictive accuracy by bringing self-reports more into alignment with actual past behavior. Interestingly, the present data do suggest that attending to past behavior does enhance predictive accuracy under certain conditions.

\section{Study 3}

Building on the correlational findings of Study 2, Study 3 attempted to explore more directly the effects of manipulating subjects' attention to different types of information on the accuracy of self-predictions. Such a manipulation could provide confirmation of the suggestive findings of Study 2 and is of relevance to efforts to enhance self-prediction accuracy in more applied assessment settings. Individuals made a series of self-predictions under one of four sets (personal base rate, personal dispositions, population base rate, or control) and later reported the occurrence or nonoccurrence of each event or behavior. Personal base-rate information, personal dispositions information, and population base-rate information were chosen for study because they were the categories that evidenced the strongest associations with accuracy in Study 2 and, in the case of population base rates, because it had theoretical relevance. On the basis of the findings of Study 2, it was predicted that subjects in the personal base-rate and personal dispositions conditions would evidence the greatest accuracy. Attention to population baserate information was not expected to enhance self-prediction accuracy and was explored only in an effort to replicate, through a different methodology, the results indicating its lack of utility in Study 2.

\section{Method}

Thirty-two male and 47 female undergraduates participated in this study to partially fulfill an introductory psychology course requirement. The procedure used to elicit and assess the accuracy of self-predictions was the same as that used in Study 2. The manipulation of the information strategy used to formulate predictions involved distributing, to each subject at random, one of four sheets containing "special instructions" to be followed in making their ratings. Each sheet contained a paragraph describing one of the three types of information: personal base rate, personal dispositions, and population base rate. The instructions, written to be as parallel in length and style as possible, asked subjects to attend specifically to the type of information described in making their ratings. For example, subjects in the personal dispositions condition ${ }^{3}$ received the following instructions:

In judging the likelihood of each event occurring in the next 2 months, we would like you to keep one question in mind. For each event, when you try to judge whether or not it may happen, ask yourself: BASED ON MY OWN PERSONAL QUALITIES OR ATTRIBUTES, OR THE KIND OF PERSON I AM, HOW LIKELY IS THIS EVEN'T TO HAPPEN TO ME? We want you simply to focus on judging your own personal qualities, likes and dislikes, and strengths and weaknesses in judging whether or not it is likely that you will engage in or experience each event or behavior. Try to assess or bring to mind your knowledge of your own personal qualities and use this information to decide whether or not each event is likely to occur.

Control subjects read a passage of similar length that contained no instructions about the type of information to be attended to. Subjects were given $5 \mathrm{~min}$ to read over the information instructions to assure they understood them before making their likelihood ratings. At the conclusion of the session, 5 subjects reported some awareness that the study assessed self-prediction accuracy. Because their mean accuracy scores did not differ from the remainder of the sample, their data were retained in the analysis.

\section{Results}

As in Study 2, we scored an item as a hit if it was predicted definitely or probably to occur and did, or if it was predicted definitely or probably not to occur and did not. Again, the main dependent variable was total number of hits. A two-way analysis of variance (ANOVA) with sex and information strategy as factors yielded a significant main effect for information strategy, $F(3,71)=3.21, p<.03$. Individuals in the personal dispositions condition had the highest mean hit rate $(M=40.7)$, followed by those in the personal base-rate condition $(M=39.6)$, control subjects $(M=38.2)$, and population base-rate subjects $(M=$ 36.5). A post hoc comparison revealed that the difference in mean number of hits between the personal base-rate and population base-rate conditions was significant, $t(75)=2.26, p<.03$. This was also true for the comparison of mean hit rate between the personal dispositions and population base-rate conditions,

\footnotetext{
${ }^{3}$ Copies of the instructions presented to subjects in the personal baserate, population base-rate, and control conditions may be obtained by writing to the first author.
} 
$t(75)=3.13, p<.003$. The difference in hit rate between the personal dispositions condition and control subjects approached significance, $t(75)=1.93, p<.06$. There were no main effects nor any interactions involving the sex of the subject.

\section{Discussion}

The results suggest that attending to certain information can influence the accuracy of self-predictions. Judgments based on personal dispositions or personal base-rate information were superior to those based on population base-rate information and control judgments. If anything, there was a tendency for subjects instructed to attend to population base rates to be less accurate than subjects in the control condition. Although the reasons for the superiority of the personal dispositions and personal base-rate strategies are not totally clear, both may orient the subject to the past frequency and/or consistency of different behaviors, allowing for a better estimate of each event's likelihood of occurrence in the future. In particular, by calling to mind relevant self-applied dispositional labels, subjects may attend to previously noted consistencies in their behavior.

The failure of population base-rate information to enhance accuracy can be explained in at least two ways. First, it may be that such information is simply less useful than more individuating information. A second possibility is that attending to population base rates is less effective because subjects cannot assess these rates accurately. Although previous research suggests that the population base rate of an event is associated with how accurately it can be predicted (Shrauger \& Osberg, 1982), the earlier work involved actual base-rate data rather than subjects' estimates of these data.

The findings of the present investigation further our efforts to understand the information strategies that may enhance accuracy of self-prediction. Future research should be directed toward such issues as the possible additive effects of attending to more than one type of information and to determining the combinations of information that result in the greatest accuracy of self-predictions. The development of an optimal instructional package would facilitate the application of these experimental findings to clinical assessment situations and other applied settings.

\section{Study 4}

In this study we examined the second general class of variables that were assumed to be relevant to the accuracy of selfpredictions, the relation between the individual and the behavior prediction. Because people cannot always be accurate in their attempts at self-prediction, knowing when to rely on a person's self-predictions is an issue that should be of concern to professionals. Study 4 attempted to identify qualities within the predictions themselves that relate to accuracy and, therefore, could serve as cues to the subsequent accuracy of such self-appraisals. The properties of predictions examined for their relation to subsequent accuracy included the confidence with which a prediction is stated and whether one's prediction for self is distinctive in comparison to what is expected for others.

With respect to the confidence or strength of a prediction, one might expect more certain self-predictions to be more accurate. Evidence from the attitude-behavior literature supports this expectation. Fazio and Zanna (1978), for example, have demonstrated that more confidently stated attitudes evidence a better fit with later behavior. It was therefore predicted that greater certainty in self-prediction would be associated with greater accuracy.

Distinctiveness of one's self-prediction (defined as predicting one's own behavior to differ from the average person's) was also explored for its relation to accuracy. Because features of the self that are perceived to be distinct from others often represent more salient dimensions of one's self-concept (McGuire, McGuire, Child, \& Fujioka, 1978; McGuire \& Padawer-Singer, 1976), an individual may "know" him or herself better on these dimensions and provide more accurate self-predictions concerning related behaviors. Thus, it was expected that distinctive predictions would be more accurate than nondistinctive predictions.

\section{Method}

Fifty-three male and 70 female subjects participated in this study to partially fulfill an introductory psychology course requirement. The procedure for eliciting and assessing the accuracy of subjects' self-predictions was the same as that described for Studies 2 and 3 with one exception. In addition to making self-predictions, half of the subjects were asked to predict the likelihood of a list of behaviors for the average student of their age and sex. The two sets of predictions were then compared in order to evaluate the effects of distinctiveness. A prediction was considered to be distinctive if the prediction for self differed from that for the average person. Five subjects reported awareness of the study's focus on self-prediction accuracy, but because their mean accuracy did not differ from the rest of the sample they were included in all analyses.

\section{Results and Discussion}

Because accuracy scores showed no main effect of or interaction with sex of subject, the results reported were collapsed across this variable.

To examine whether more certain predictions result in greater accuracy, each subject's predictions were categorized into definite versus probable predictions. The percentage of accurate predictions was then computed for each category and compared across subjects. A repeated measures ANOVA yielded a significant main effect for certainty of prediction, with more definite predictions being more accurate an average of $80.6 \%$ of the time as compared with $60.2 \%$ accuracy for probable predictions, $F(1,121)=233.18, p<.00001$.

A potential problem in interpreting this finding involves the confounding of certainty with item content. People may have been more certain about highly predictable items such as those with extreme base rates. To control for the possible effects of item content, a similar repeated measures analysis was performed that treated items as the unit of analysis. For each item, the percentage accuracy of subjects who made definite predictions and those who made probable predictions was computed and entered into a repeated measures ANOVA. A similar main effect of certainty of predictions was observed with the percentage accuracy of definite predictions exceeding that of probable predictions $(M \mathrm{~s}=76.6 \%$ and $63.0 \%$, respectively), $F(1,54)=$ 
$91.06, p<.00001$. The foregoing analyses, both within subjects and within items, support the contention that more certain predictions are likely to be more accurate.

The relation between distinctiveness and accuracy was explored by categorizing each prediction as either distinctive (subjects' prediction for self differed from their prediction for the average person) or nondistinctive (subjects' prediction for self and average other were the same). Within-subjects analysis revealed distinctive self-predictions to be on the average more accurate than nondistinctive self-predictions although the difference was not as large as that observed for the certainty variable ( $M \mathrm{~s}=67.5 \%$ and $63.0 \%$, respectively), $F(1,58)=4.25, p<$ .05 . A within-items analysis also produced a main effect for the distinctiveness variable consistent with the above finding ( $M \mathrm{~s}=$ $68.9 \%$ and $61.3 \%$, respectively), $F(1,54)=5.53, p<.03$.

The findings of the present investigation have provided evidence that certain properties of people's self-predictions may serve as important cues to the accuracy of such judgments. These findings have practical utility in that they provide assessors with an important set of cues for deciding how much to rely on a client's self-reports. The results for certainty suggest that, in stating predictions with varying degrees of confidence, people may be making an implicit self-evaluation of their likelihood of being accurate. However, a clear difference exists between the present experimental situation and most clinical situations. In the present study, subjects were unaware of the extent to which their self-predictions were being used, particularly that their judgments were being evaluated for accuracy. One might argue that if subjects were aware that accuracy was being evaluated, self-presentation motives would have entered in and suppressed the tendency for more certain predictions to be more accurate. On the other hand, in clinical contexts, clients' motivation toward improvement and situational demands for candor may offset their desires to present themselves favorably.

Along with further attention to the certainty variable, future attempts to examine the distinctiveness variable would appear to be fruitful. Continued efforts to explore the relation of these and other variables to accuracy in self-prediction will aid those in applied settings in knowing when self-assessments may be most profitably used in the decision-making process.

\section{General Discussion}

The results of the four investigations reported here provide a beginning in our efforts to understand individuals' self-prediction processes. The present findings have shed light on the types of information people use when formulating self-predictions, the kinds of information that seem useful to developing accurate self-predictions, and the aspects of predictions and predictors that are associated with accuracy. The dominant theme throughout the results of these investigations is that people seem to draw on individuating information about themselves when making predictive judgments and that when they do, their judgments are more accurate.

Assessing one's own past frequency of behavior proved to be a more effective self-prediction strategy than relying on less individuating information such as population norms or the situational circumstances related to engaging in a behavior. $A$ focus on one's own distinctive qualities, in particular, showed a strong association with accuracy in self-prediction. This was apparent not only in the finding that attention to one's personal dispositions was related to enhanced accuracy but also in the results demonstrating that when people predict their behavior to be different from others they are more accurate than when they see themselves as similar.

The individual differences findings were also consistent with the theme that attention to individuating factors enhances the validity of self-predictions. At least among male subjects, higher private self-consciousness or heightened attention to self-relevant information was associated with greater accuracy. For both sexes, higher public self-consciousness, which indicates more concern with self-presentation and less attention to individuating characteristics of the self, was associated with less accuracy. Although Paunonen and Jackson (1985) have criticized efforts to identify individual differences in or moderators of the extent to which peoples' behavior is predictable from obtained personality data (such as differences in the consistency of the individual's behavior-Bem \& Allen, 1974), the present data regarding individual differences in self-prediction accuracy are consistent with numerous studies that have demonstrated that private and public self-consciousness moderate the congruence between self- and peer assessments of the individual (Cheek, 1982; Underwood \& Moore, 1981; Wymer \& Penner, 1985) as well as the fit between self-assessments and actual behavior (Scheier, 1980; Scheier et al., 1978; Shrauger \& Osberg, 1982; Turner, 1978; Turner \& Peterson, 1977; Wymer \& Penner, 1985).

The present results suggest that in applied assessment settings individuals might be directed to attend to their past experience relevant to the behavior predicted and to more focused and idiosyncratic aspects of their personal qualities that might be related to that behavior. The findings for self-consciousness suggest that interventions aimed at increasing attention to one's personal attributes and reducing self-presentational concerns would also prove useful. Finally, assessment practitioners might well attend to the certainty of people's self-predictions as a cue to the potential accuracy of such judgments. Perhaps the strongest predictor of self-prediction accuracy was the certainty with which people stated their self-predictions. An individual's confidence in stating a prediction was strongly associated with accuracy, and this effect occurred independent of the base rate of the events predicted. People seem to have some knowledge about the potential accuracy of their predictions and this might usefully be attended to in evaluating their judgments.

One potential concern in the present research is the self-report criterion for occurrence of events. This becomes important particularly if subjects were aware of the self-prediction focus of the studies and were led by a desire to appear consistent or accurate through biased reporting of events' occurrence. Several procedures were designed to minimize biased reporting: The self-prediction focus of the accuracy studies was disguised; clear-cut and easily discernible events were used as targets; and a 2-month interval separated predictions from reports of events' occurrence. The fact that only 13 of the 264 subjects used in the three accuracy studies reported any awareness of the studies' self-prediction focus suggests that these measures were generally effective. Furthermore, there were no differences in accuracy levels for people who felt accuracy was being assessed and those who did not. 
These findings suggest that subjects did not bias their reports of events' occurrence by bringing them into line with their predictions; however, a more subtle type of bias might still have occurred. Making predictions about a list of events, or simply being exposed to them, might sensitize one to those events and thereby influence their later reported occurrence in at least two ways. One possibility is that making predictions about certain behaviors may render those behaviors more salient and, therefore, more likely to be engaged in. Alternatively, the enhanced salience of behaviors about which one has made predictions might make those behaviors more available to subsequent recall and, therefore, more likely to have been reported to have occurred. To explore these possibilities, Shrauger and Osberg (1985), using procedures paralleling those used in the present research, had some subjects make self-predictions of a set of events, had others make ratings of the events but no predictions, and had a third group receive no exposure to the events at all. If making predictions of the events or mere exposure to them influenced subjects' later experience and/or reporting, different rates of events' occurrence might have been expected between the 3 groups, particularly for highly desirable or undesirable events (Sherman, 1980). No differences were found, however, indicating no support for the contention that attending to or predicting events influences reports of their subsequent occurrence.

Although the present studies have helped to illuminate the parameters of self-prediction accuracy, several aspects of the findings deserve continued attention. For example, a limitation of the findings concerning people's use of personal base-rate information is that their actual or perceived personal base rates were never really measured. The data indicated that people do use this type of information and that when they do their judgments were usually more accurate, but no information on how people use these data was available. If a person has frequently engaged in a behavior, does this usually lead to predicting the occurrence of that behavior? Will a history of rare performance of a behavior lead to predicted nonoccurrence? An important variable to take into account here may be the time span covered by the prediction. Predictions may be more likely to match past base rates if the time span covered by a prediction is short. A person may have had very few arguments with friends in the past and predict none to occur within the next week or two; however, the prediction might be different if it involves judging the likelihood of an argument ensuing during the next 6 months or a year.

Also, when people attend to personal base rates as a basis for self-prediction, how wide is their information search? Do people scan the full range of their past experiences or do more recent experiences have a disproportionate influence? Some theorists have speculated that self-descriptions are usually based on more recent experiences (Bem \& McConnell, 1970). It is even possible that perceptions of personal base rates may be based on one salient experience. The usefulness of perceived personal base rates based on more narrow information searches would seem to be less than that of those based on a broader search, although this assumption should be tested empirically.

Attention to one's personal dispositions also proved to be an effective self-prediction strategy, but it is likely to be more useful at some times than at others. When predicting behaviors gov- erned by dispositional dimensions on which people have developed a firm self-evaluation, accuracy seems more likely than for behaviors wherein the individual has no firm self-evaluation for related dispositions. In Markus's (1977) terms, individuals are likely to be more accurate if their self-predictions are based on dimensions for which they have relevant self-schemata, which are defined as firm cognitive generalizations about the self. Although the schematicity of the dispositions to which individuals attended was not evaluated in the present research, it would seem that attention to relevant personal dispositions will be particularly useful if this information is schematic.

The findings relating certainty of self-predictions to accuracy were consistent with those of Fazio and Zanna (1978), who found that more confident attitudes, manipulated experimentally, demonstrated a better fit with later actual behavior. The present results demonstrated this effect with naturally varying certainty, not manipulated confidence, and the effect was demonstrated across a variety of behaviors rather than across a circumscribed set of behaviors as was true in the Fazio and Zanna study. These findings are also consistent with those of Bandura (1977) and numerous other researchers who have reported that the strength of subjects' self-ratings of the ability to engage in fear-inducing behavior is highly correlated with subsequent behavior in fear-inducing situations.

Previous efforts to examine the personal qualities related to the ability to give accurate and predictive self-judgments have centered on the self-consciousness variable. Future research should continue to explore the potential relations of other personal factors such as intelligence and curiosity as they relate to self-prediction accuracy. Cacioppo and Petty's (1982) concept of need for cognition, which they describe as measuring differences in "the tendency for an individual to engage in and enjoy thinking" (p. 116), is an additional dimension that may relate to the tendency to engage in spontaneous self-prediction and to self-prediction accuracy.

Other questions about the phenomenon of self-prediction deserve future attention as well. For example, the question of whether certain types of behaviors are more predictable than others should be a focus. Although Osberg (1983) concluded that accuracy was very target specific because dimensions such as the social desirability, emotionality, and evaluativeness of events were unrelated to the accuracy with which they were predicted, future research should continue to examine the possible dimensions of behaviors that may render them more predictable.

Finally, a careful analysis should be undertaken of the role accurate self-prediction may play in psychological adjustment. Not only might a better understanding of self-prediction processes enhance efforts to improve behavior prediction, it may also represent an avenue to assist people in developing more effective personal functioning. Becoming an accurate self-predictor may allow the person to better appraise potential outcomes of various actions and to select the appropriate behavioral alternative that will maximize gains.

\section{References}

Allport, G. W. (1942). The use of personal documents in psychological science. (Social Science Research Council, Bulletin 49). Ann Arbor, MI: Edwards Brothers. 
Bandura, A. (1977). Self-efficacy: Toward a unifying theory of behavioral change. Psychological Review, 84, 191-215.

Bem, D. J., \& Allen, A. (1974). On predicting some of the people some of the time: The search for cross-situational consistencies in behavior. Psychological Review, 81, 506-520.

Bem, D. J., \& McConnell, H. (1970). Testing the self-perception explanation of dissonance phenomena: On the salience of premanipulation attitudes. Journal of Personality and Social Psychology, 14, 23-31.

Billings, A. G., Cronkite, R. C., \& Moos, R. H. (1983). Social-environmental factors in unipolar depression: Comparisons of depressed patients and nondepressed controls. Journal of Abnormal Psychology, 92, 119-133.

Bower, G. H., \& Gilligan, S. G. (1979). Remembering information related to one's self. Journal of Research in Personality, 13, 420-432.

Bradley, G. W. (1978). Self-serving biases in the attribution process: A reexamination of the fact or fiction question. Journal of Personality and Social Psychology, 36, 56-71.

Burisch, M. (1984). Approaches to personality inventory construction. American Psychologist, 39, 214-227.

Cacioppo, J. T., \& Petty, R. E. (1982). The need for cognition. Journal of Personality and Social Psychology, 42, 116-131.

Chapman, L. J., \& Chapman, J. P. (1967). Genesis of popular but erroneous psychodiagnostic observations. Journal of Abnormal Psychology, 72, 193-204.

Cheek, J. M. (1982). Aggression, moderator variables, and the validity of personality tests: A peer-rating study. Journal of Personality and Social Psychology, 43, 1254-1269.

Coates, T. J., Killen, J. D., George, J., Marchini, E., Silverman, S., \& Thoresen, C. (1982). Estimating sleep parameters: A multitrait-multimethod analysis. Journal of Consulting and Clinical Psychology, 50, 345-352.

Crowne, D. P., \& Marlowe, D. (1964). The approval motive. New York: Wiley.

Dana, R. (1984). Megatrends in personality assessment: Toward a human science professional psychology. Journal of Personality Assessment, 48, 563-579.

Edwards, A. L. (1957). The social desirability variable in personality assessment and research. New York: Dryden.

Fazio, R. H., \& Zanna, M. P. (1978). Attitudinal qualities relating to the strength of the attitude-behavior relationship. Journal of Experimental Social Psychology, 14, 398-408.

Fazio, R. H., \& Zanna, M. P. (1981). Direct experience and attitudebehavior consistency. In L. Berkowitz (Ed.), Advances in experimental social psychology (Vol. 13, pp. 162-202). New York: Academic Press.

Fenigstein, A., Scheier, M. F., \& Buss, A. H. (1975). Public and private self-consciousness: Assessment and theory. Journal of Consulting and Clinical Psychology, 43, 522-527.

Hogan, R., Hogan, J., Briggs, S., \& Jones, W. (1983). Sense, nonsense, and the use of personality measures. Journal of Research in Personality, $17,451-456$.

Jones, E. E., \& Nisbett, R. E. (1971). The actor and the observer: Divergent perceptions in the causes of behavior. New York: General Learning Press.

Kahneman, D., \& Tversky, A. (1973). On the psychology of prediction. Psychological Review, 80, 237-251.

Kelley, H. H. (1967). Attribution in social psychology. Nebraska Symposium on Motivation, 15, 192-238.

Kelley, H. H. (1973). The process of causal attribution. American Psychologist, 28, 107-128.

Kelly, G. A. (1955). The psychology of personal constructs. New York: Norton.

Korchin, S. J., \& Schuldberg, D. (1981). The future of clinical assessment. American Psychologist, 36, 1147-1158.
Kuiper, N. A. (1981). Convergent evidence for the self as a prototype: The "Inverted-U RT Effect" for self and other judgments. Personality and Social Psychology Bulletin, 7, 438-443.

Lanyon, R. I. (1984). Personality assessment. Annual Review of Psychology, 35, 667-701.

Lewinsohn, P. M., Mischel, W., Chaplin, W., \& Barton, R. (1980). Social competence and depression: The role of illusory self-perceptions. Journal of Abnormal Psychology, 89, 203-212.

Major, B. (1980). Information acquisition and attribution processes. Journal of Personality and Social Psychology, 39, 1010-1023.

Markus, H. (1977). Self-schemata and processing information about the self. Journal of Personality and Social Psychology, 35, 63-78.

Markus, H., Crane, M., Bernstein, S., \& Siladi, M. (1982). Self-schemas and gender. Journal of Personality and Social Psychology, 42, 38-50.

McGuire, W. J., McGuire, C. V., Child, P., \& Fujioka, T. (1978). Salience of ethnicity in the spontaneous self-concept as a function of one's ethnic distinctiveness in the social environment. Journal of Personality and Social Psychology, 36, 511-520.

McGuire, W. J., \& Padawer-Singer, A. (1976). Trait salience in the spontaneous self-concept. Journal of Personality and Social Psychology, 33, 743-754.

Mischel, W. (1968). Personality and assessment. New York: Wiley.

Mischel, W. (1977). On the future of personality measurement. American Psychologist, 32, 246-254.

Nicholls, J. G., Licht, B. G., \& Pearl, R. A. (1982). Some dangers of using personality questionnaires to study personality. Psychological Bulletin, 92, 572-580.

Nisbett, R. E., \& Borgida, E. (1975). Attribution and the psychology of prediction. Journal of Personality and Social Psychology. 32, 932943.

Nisbett, R. E., \& Ross, L. (1980). Human inference: Strategies and shortcomings. Englewood Cliffs, NJ: Prentice-Hall.

Nisbett, R. E., \& Wilson, T. D. (1977). Telling more than we can know: Verbal reports on mental processes. Psychological Review, 84, 231259.

Osberg, T. M. (1983). Exploring the process and parameters of self-prediction (Doctoral dissertation, State University of New York at Buffalo, 1982). Dissertation Abstracts International, 43, 3038B.

Paunonen, S. V., \& Jackson, D. N. (1985). Idiographic measurement strategies for personality and prediction: Some unredeemed promisory notes. Psychological Review, 92, 486-511.

Pryor, J. B. (1980). Self-reports and behavior. In D. M. Wegener \& R. R. Vallacher (Eds.), The self in social psychology (pp. 206-228). New York: Oxford University Press.

Pryor, J. B., Gibbons, F. X., Wicklund, R. A., Fazio, R. H., \& Hood, R. (1977). Self-focused attention and self-report validity. Journal of Personality, 45, 513-527.

Regan, D. T., \& Fazio, R. H. (1977). On the consistency between attitudes and behavior: Look at the method of attitude formation. Journal of Experimental Social Psychology, 13, 28-45.

Rogers, T. B., Kuiper, N. A., \& Kirker, W. S. (1977). Self-reference and the encoding of personal information. Journal of Personality and Social Psychology, 35, 677-688.

Rorer, L. G., \& Widiger, T. A. (1983). Personality structure and assessment. Annual Review of Psychology, 34, 431-463.

Ross, L. (1977). The intuitive psychologist and his shortcomings: Distortions in the attribution process. In L. Berkowitz (Ed.)., Advances in experimental social psychology (Vol. 10, pp. 173-220). New York: Academic Press.

Rotter, J. B. (1966). Generalized expectations for internal versus external control of reinforcement. Psychological Monographs, $80(1$, Whole No. 609).

Scheier, M. F. (1980). Effects of public and private self-consciousness on 
the public expression of personal beliefs. Journal of Personality and Social Psychology, 39, 514-521.

Scheier, M. F., Buss, A. H., \& Buss, D. M. (1978). Self-consciousness, self-report of aggressiveness and aggression. Journal of Research in Personality, 12, 133-140.

Schlenker, B. R. (1980). Impression management: The self-concept, social identity, and interpersonal relations. Belmont, CA: Wadsworth.

Sherman, S. J. (1980). On the self-erasing nature of errors of prediction. Journal of Personality and Social Psychology, 39, 211-221.

Shrauger, J. S. (1985). Development and validation of a self-confidence scale. Unpublished manuscript, State University of New York at Buffalo.

Shrauger, J. S., \& Osberg, T. M. (1981). The relative accuracy of selfpredictions and judgments by others in psychological assessment. Psychological Bulletin. 90, 322-351.

Shrauger, J. S., \& Osberg, T. M. (1982). Self-awareness: The ability to predict one's future behavior. In G. Underwood (Ed.), Aspects of consciousness (Vol. 3, pp. 267-313). London: Academic Press.

Shrauger, J. S., \& Osberg, T. M. (1985). The effects of predictions on the reported occurrence of behaviors. Unpublished manuscript.

Sobell, L. C., \& Sobell, M. B. (1975). Outpatient alcoholics give valid self-reports. Journal of Nervous and Mental Disease, 161, 32-42.

Sobell, L. C., \& Sobell, M. B. (1978). Validity of self-reports in three populations of alcoholics. Journal of Consulting and Clinical Psychology, 46, 901-907.

Stunkard, A. J., \& Albaum, J. M. (1981). The accuracy of self-reported weight. American Journal of Clinical Nutrition, 34, 1593-1599.

Trope, Y. (1983). Self-assessment in achievement behavior. In J. Suls \&
A. G. Greenwald (Eds.), Psychological perspectives on the self (Vol. 2, pp. 93-121). Hillsdale: NJ: Erlbaum.

Turner, R. G. (1978). Consistency, self-consciousness, and the predictive validity of typical and maximal personality measures. Journal of Research in Personality, 12, 117-132.

Turner, R. G., \& Peterson, M. (1977). Public and private self-consciousness and emotional expressivity. Journal of Consulting and Clinical Psychology, 45, 490-491.

Underwood, B., \& Moore, B. S. (1981). Sources of behavioral consistency. Journal of Personality and Social Psychology, 40, 780-785.

U.S. Department of Justice, Bureau of Justice Statistics. (1985). Examining Recidivism (Publication No. NCJ-96501). Washington, DC: U.S. Government Printing Office.

Warshaw, P. R., \& Davis, F. D. (1985). Disentangling behavioral intention and behavioral expectation. Journal of Experimental Social Psychology, 21, 213-228.

Watson, D. (1982). The actor and the observer: How are their perceptions of causality divergent? Psychological Bulletin, 92, 682-700.

Weber, R. P. (1985). Basic content analysis. (Sage University Paper Series on Quantitative Applications in the Social Sciences, Series No. 07-049). Beverly Hills, CA: Sage.

Wicklund, R. A., \& Gollwitzer, P. M. (1983). A motivational factor in self-report validity. In J. Suls \& A. G. Greenwald(Eds.), Psychological perspectives on the self (Vol. 2, 67-92). Hillsdale, NJ: Erlbaum.

Wiggins, J. S. (1973). Personality and prediction: Principles of personality assessment. Reading, MA: Addison-Wesley.

Wymer, W. E., \& Penner, L. A. (1985). Moderator variables and different types of predictability: Do you have a match? Journal of Personality and Social Psychology, 49, 1002-1015. 
Appendix

\section{Life Events Questionnaire}

1. Become very upset with or had an argument with a very close friend.

2. Gone an entire night without sleep.

3. Gone to services at a church or synagogue.

4. Been a patient in a hospital or infirmary because of some physical problem.

5. Gone into finals with a grade of $\mathrm{C}$ or below in at least one course.

6. Introduced yourself to someone you are attracted to.

7. Started to play a new sport or physical activity you had not done before.

8. Gone on a diet.

9. Offered advice to a friend concerning his or her romantic relationship.

10. Attended a concert for which an admission was charged.

11. Skipped a class because you simply didn't feel like attending.

12. Met someone new with whom you would like to have a romantic relationship.

13. Agreed with someone or said something you didn't mean or feel so as not to hurt their feelings.

14. Treated someone to a meal in a restaurant or a night out.

15. Will not have had enough money to pay an important bill.

16. Will at some point feel generally dissatisfied with the way your life is going.

17. Said something in class which the instructor or another class member criticized or disagreed with.

18. Been to a party or social gathering where you felt badly enough about the way you behaved that you worried about it the next day.

19. Made a joke or humorous comment in a group of at least five people which they laughed at.

20. Will have felt forced to tell someone important to you something negative about themselves which you did not want them to hear.

21. Will have refused to do something that other people wanted you to do even though you thought it might cost you their friendship.

22. Will have written a paper, done a project, or done an exam that you felt was the best you had ever done.

23. Will have changed your plans regarding what you will mainly be doing in the summer (going to school or working, type of work will be doing).

24. Found yourself refereeing an argument between friends or members of your family.

25. Went to a class unprepared for the discussion because you had not done the required reading.

26. Had to have some dental work done.

27. Changed your hairstyle or type of haircut.
28. Will have been unable to sleep for at least an hour after going to bed because you were thinking about some important decision or event.

29. Gotten high on some type of drug besides alcohol.

30. Begun to work particularly hard on some activity in which you currently lack confidence.

31. Will have been in a situation in which your performance was poorer than usual because you were anxious.

32. Go into final exams with a grade of $A$ in at least one course.

33. Will have ended a romantic relationship.

34. Bought a phonograph record.

35. Will have had some type of sexual experience which you have not had previously.

36. Have fallen in love.

37. Will have read at least one book that was not assigned or recommended for a course.

38. Have had period of a day or more when you could get very little done because you feel too down and discouraged.

39. Will have had sexual relations.

40. Become intoxicated.

41. Will have gone out and partied when you should have been studying for exams.

42. Eaten your main meal of the day alone.

43. Had an argument with one of your parents that was serious enough for you to be concerned about it the following day.

44. Met someone new whom you expected to be a close friend for years to come.

45. Eaten a type of food you have never had before.

46. Been awakened from your sleep by an unpleasant dream.

47. Gone to a movie.

48. Been rejected by a group of people who were important to you.

49. Participated in a group sports activity.

50. Fretted or worried on and off for at least three days about something someone said that angered or upset you.

51. Had a sexual experience that was frustrating or unsatisfying.

52. Parents or family members will have complained to you about some important aspect of your behavior of which they disapprove.

53. Will have learned that someone whom you thought liked you said something unfavorable about you.

54. You will have become jealous of someone else's good fortune.

55. You will have begun to smoke cigarettes or increased your cigarette smoking.

Received October 10, 1985

Revision received February 13, 1986 